\title{
The Prevalence of Environment Related Diseases in Peri-Urban Areas of Ogbomoso, Nigeria \\ ${ }^{1}$ Adeboyejo A Thompson, ${ }^{1}$ Abolade Olajoke And ${ }^{10}$ shinowo Temitope
}

\section{Abstract}

Within the context of existing socio-physical and housing environmental conditions, this paper examines the prevalence of environment related communicable diseases in eighteen peri-urban communities in Ogbomoso, Nigeria. The study combined a social survey of residents perception and six months hospital records of clinically diagnosed diseases to examine the incidence, prevalence, gender and spatial dimensions of four major communicable diseases for which secondary data was available-malaria, typhoid, cholera and diarhoea.

The study revealed a general lack of basic infrastructural facilities and services. While houses were mainly of the bungalow type (72\%) and owner occupied (63.5\%), accessibility to houses was generally poor. A significant proportion of the houses (26.5\%) had no toilet while, about 99 per cent of the respondents did not have access to pipe-borne water with 80 percent using nearby vacant land as refuse dump. The most prevalent diseases were malaria (53.5\%) and typhoid (42.2\%). The only cases of Cholera (2.2\%) and diarhoea (2.2\%), were recorded in Abaa community in Surulere Local Government Area. In all cases, Females were more vulnerable to malaria and typhoid (56.2\% and $61.2 \%$ ) than their male counterparts. Preparation of layout plans and close monitoring of development at the periurban areas and urgent provision of basic facilities and services are suggested.

\section{Introduction}

he relationship between man and
the environment is a complex web of interactions with causal and consequential interrelationships. While man, largely through urbanization and industrialisation continues to make significant changes to global environment, the scope and severity of impact and implications of urban growth and the consequential emergence of the peri-urban areas of cities, continues to expand with debilitating effects on man at the peri-urban areas. From the point of view of environmental and health implications, there are at least, three main reasons for the development of periurban areas.

First, is the increasing level of urbanization and consequential congestion of, and as well as creation of slum conditions in the core areas of the city. For instance, the need to escape from the congestions of the city centres led to the emergence of suburb settlements called "bedroom communities" on the outskirts of cities in the United Kingdom, Australia and the US in the $19^{\text {th }}$ Century (Rugg, 1972; Weber (1963). In many cities of developing world, increasing population concentration has left many cities gasping (Egunjobi, 1999) leading to population explosion and exodus to the periurban areas.

Secondly, and closely related to the above is improvement in transportation, particularly, intra-city highways and use of automobiles, which have resulted in the creation of transport dependent periurban areas of cities. This development has facilitated emergence and growth of residential areas at the outer parts of the urban areas. In North America and many developing countries particularly since independence, improvements in both intra and inter city road network coupled with increasing trend in car ownership accelerated living away from the urban centres. World wide, the result is increasing concentration of population and activities in the suburbs relative to the city. In developing countries in particular, the rate and pace of this movement and the associated pace of residential development at the suburbs are alarming. Equally puzzling is the observable morphology which in all respect is reminiscence of the core of traditional cities.

Thirdly, all the above factors have been aggravated by the acute shortage of accomondation and high cost of land for development in the city centre and the availability of cheaper plots and acommondation at the urban outskirts in both developed and developing nations thereby making the suburbs economically and socially attractive for prospective developers as well as people and activities.

No doubt, the impact of city growth on the environment is one of the most documented in urban development research, (Xie et al, 2005; 2006; Hadoy et al, 2001; Jaiyebo, 2003; Adriana and Julio, 2003; Van den Berg et al, 2003 ). However, as observed by Adeboyejo and Abolade (2007), while

1Department of Urban and Regional Planning Ladoke Akintola University of Technology, Ogbomoso. Nigeria thompsonadeboyejo@yahoo.com 
research attention continues to be riveted on the environmental consequences of urbanization, there is little or no empirical evidence on the relationship between city expansion and health of the people, particularly those in the peri-urban areas, where food, water and energy required in the cities are obtained and city wastes are dumped. Although the measurement of direct relationship between urban expansion and health of the people at the hinterland area is difficult in an empirical investigation, but against the background of increasing urban population pressure on housing, land and other environmental resources at the periurban areas, and the facts that, the destination of the bulk of urban solid waste is the immeditate city hinterland, away from the supervisory eyes of urban municipal waste management authority and where waste management facilities are lacking and capacity for enforcement of environmental regulations is weak or non existence, the health implications of periurban development are obvious.

This study is therefore concerned with the physical environmental conditions of periurban communities and the health of the people. Attention is focused on the incidence and prevalence of certain environment related communicable diseases, both as reported by the peri-urban dwellers and as indicated by hospital records. The objectives are to: examine the housing and environmental condition in the area under consideration and, assess the incidence and prevalent rates of four environment related communicable diseasesmalaria, typhoid, cholera and diarhoea.

\section{Theoretical Framework and literature Review}

Several concepts such as periurban, sprawl, suburbanization, health, public/environmental health, healthy city etc. are relevant in an empirical investigation of such issues as communicable diseases in periurban areas. A few of these are addressed so as to provide the discussion with a consistent notation. Also the contextual relevance of central place theory to the present discussion is examined.

The term periurban has been variously referred to as, "urban frontier" "suburbs", rural-urban fringe" etc. and generally defined as the outlying districts at the fringe areas of the city (Rugg 1972), which in most cases serve as buffer for future urban development (Adesina 2007). The periurban issue is not a new phenomenon, because in the Greek times, the new gymnasium was located at the fringe of the "polis" and, commercial settlements outside the gate of the walled medieval cities were typologies of the suburbs. But, since the turn of the 20th century, and in different parts of the world, particularly in United States and Western Europe, the trend became pronounced as large number of people could live and work in the fringe areas of cities, so as to capture the advantages of the fringe areas (Yeates et al, 1980). In any case, many of the neighbourhoods within large metropolitan areas were once suburbs of such, and so the current suburbs of many other areas, through the process of suburbanization or urban sprawl will be incorporated into city metropolis, while newer suburbs will be created.

Again, the general usage of the term sprawl suggests it is a pattern and pace of land development (usually at the urban fringe) in which the rate of land consumed for urban purposes, exceeds the rate of population growth and which results in an inefficient and consumptive use of land and its associated resources (Valerie 2000). No doubt, the process not only results in destruction of green space, hapharzard development pattern, poor and most often, lack of infrastructural facilities and services, promotion of illhealth, it increases traffic and environmental pollution since development is often poorly(if at all) monitored.

The potential presence of ccommunicable diseases is obviously a feature of life in human settlement environment. Health in the context of human settlements therefore will include the whole field of environmental health (or community medicine) that is concerned with the epidemiology of as well as, the prevention and treatment of communicable and non -communicable diseases, and the provision of health education and of health care including family health. The issue of housing, environment and the provision of good housing also fall within the ambit of environmental health. The health principles for ideal settlements in which people could live harmoniously have been identified by (WHO 2004) to include:

(i) an environment free from local health hazards whether communicable disease, including water -borne and food-borne 
diseases and those spread by poor environmental sanitation, air pollution e.t.c.

(ii) good social welfare services ensuring adequate financial provision for sickness, unemployment and old age, including a satisfactory standard of living and quality of life to ensure an adequate food supply, satisfactory housing, satisfying employment, the provision of public infrastructures, and the development of personality and freedom from undue stress and anxiety.

The central Place theory is briefly reviewed here particularly with respect to its relevance to health and environmental planning in settlement systems. The central place theory as formulated by Walter Christaller in 1933 was essentially designed to explain service element in the spatial structure of a region. In the process, Christaller identified seven levels of central places comprising of hamlets, villages, sub-towns, towns, major towns, major cities and metropolitan cities in southern Germany, which all vary in sizes, spacing and functions, from the simplest and closest to the most distant and complex. One major implication of the theory is the organic relationship among settlements in a regional space. The relationship is in form of flow of goods, services and movement of people, thus requiring that no one settlement should be examined in isolation, but as part of a total system of such places. According to Funnell (1978), it means that major urban centre and their immediate rural hinterlands, and mother settlements and their offspring villages, large rural centres and their surrounding hamlets can not be planned in isolation. Central place theory placed emphasis on provision of services at each level of settlements so as to improve the standards of living of the rural dwellers and reduce rural - urban migration. This proposition and the arguement of growth pole theory formulated by Perrous (1964) and modified by Bourdeville (1966) has been used as a policy instrument for regional development in many countries. The result however, is growing disproportionate concentration of investments in major cities in the developing countries, a situation that have aggravated the conditions of poverty and distress in rural hinterlands leading to outflow of rural-urban migrants for most part of the $19^{\text {th }}$ century and early independence. There is however a reversal of this trend today as overconcentration of investment and activities in the cities have accentuated environmental and housing distresses in the cities leading to population exodus into the rural areas in search of greener and stress free environment. This type of understanding will guide the delineation of a functional region, that will serve as an environmental and health planning unit.

In recent years, the rate and pace of urban expansion and incursion into the rural hinterlands has been phenomenal, with consequential increase in suburban populations and development (Hall,2002, Adesina, 2007). This is more so in the developing countries where spatial expansion of cities and incorporation of urban fringes into the main urban land use has continued unabated. The process has often been termed "urban sprawl", viewed as development of extensive residential suburb around core cities producing a morphology that is characterized by a complex and most often hapharzard pattern of land use, poor transport network, and mixed social and economic characteristics (Yeates et al, 1980; Rugg, 1972). As cities extend into rural areas, large tracts of land are developed in a lowdensity residential area, with poor (and in most cases, lack of) infrastructural facilities and services. In most American metropolitan areas as well as cities of developing nations, the bulk of new housing is in large tract developments beyond the city edge in a search for inexpensive rural land with few (if any) restrictions on land use or building practices.

The U.S. Department of Housing and Urban Development estimates that urban sprawl consumes some 200,000 ha (roughly 500,000 acres) of farmland every year (Cunningham and Cunningham 2008). As the number increases, it becomes increasingly important to understand the reason behind the emergence of these communities, the dynamics of their growth and their changing spatial structures and in particular the implications on human health. As cities expand in to the hinterland, there is a shift of capital investment and economic opportunity from the center to the periphery. The move to the suburbs reflects a lifestyle preference shared by many developing areas (World Bank 2007). Such major shifts in the nation's demographics and in the form of our environment also have health implications, which may be positive or negative. Some of these impacts (in the 
developed countries), relate directly to the heavy reliance on automobiles: air pollution, automobile crashes, and pedestrian injuries and fatalities. Urban pollution and poor management of municipal waste (sewage and refuse) add to the health hazards. Numerous industries, from pulp to petroleum, dump untreated and often toxic liquids in open gutter, streams, rivers, lagoons and vacant lands at the urban fringe. And as elsewhere, motor vehicles contaminate the air, land and water (Elizabeth 1996). The health hazards of air pollution are well known. According to (Lvosky (2001), in sprawling countries around the world, an estimated 0.5million - 1.0million people die prematurely each year as a result of exposure to urban air pollution. Thousands of premature deaths and millions of cases of respiratory illness are associated with air pollution in such countries. Exposure to lead contributes to behavioural problems and learning disabilities in urban children (World Bank 2007; Hughes and Lovei 1999). A diverse group of urban planners and public health experts, found that people who live in countries with high "sprawl indexes" were more likely to have a higher Body Mass Index, or BMI (a standard measure of weight-toheight used to determine overweight or obesity) than people living in more compact countries (Debra et al 2007).

However, in the cities of developing nations, health impacts will arise from or be compounded by harphazard land use patterns, population pressure on housing, lack of facilities and basic services such as water and sanitation, electricity and, poor environmental sanitation. On potable water supply it has been observed that in many African countries, the women and children (who are traditionally carriers of wood and fetchers of water) spend more than half of their working days in quest of water. (World Bank, 2007). These sources are almost invariably polluted and contaminated with human and animal wastes, giving rise to high incidence of water - borne and water related disease which cause death to the young and kill or cripple the adults. [World bank 2007]. With respect to sanitation, it is estimated that only one-third of suburban residents in developing countries have satisfactory sanitation services and few cities in developing countries can afford to build modern waste treatment systems for their rapidly growing populations. (World Bank,
2007). The health implications include high prevalence rates of environment related communicable diseases such as malaria, typhoid, diarhoea etc. For instance, it is now well established that populations with Malaria are on the increase in the urbanizing tropical world, especially in unsanitary fringe areas of towns, where community waste disposal facilities are lacking, and water containing wastes makes excellent Anopheles breeding sites (Sofoluwe et al. 2006). The development and human challenge posed by malaria in Africa is unprecedented. In many countries, the epidemic has cut life expectancy and robbed society of millions of people in their prime working years. It has dimmed the hope of living full and productive lives for unimaginable number of children and adults. (World Bank 2007). This study therefore seeks to analyse the environmental conditions and associated illhealth in the periurban areas of a Nigerian city.

\section{The Study Area}

The study area of this research is the eighteen peri-urban communities of Ogbomoso as identified by (Adeboyejo and Abolade, 2007). The city of Ogbomoso is a pre-colonial urban center and the second largest city, both in terms of population and spatial extent, in Oyo State, Nigeria. The city is located at a distance of about $100 \mathrm{~km}$ north of Ibadan, the Oyo State capital, and about $80 \mathrm{~km}$ from both Ilorin and Osogbo, respectively the Kwara and Osun State capitals ( Figure 1). It is one of the main gateways to the northern part of Nigeria from the Yoruba land. It is bounded by the river Ora to the east, while no major physical barrier is encountered to the north, west and south. It develops laterally towards the north and south along the Ibadan-Ilorin road.Currently, Ogbomoso is comprised of four Local Government Areas, these are:Ogbomoso North and South, Surulere and Orire. The city is surrounded by a number of villages and medium sized towns such as Ikoyi, Odo-Oba and Iressa Apa which all have organic linkage with it, but at distances considered far enough to be out of the range of influence of expansion of Ogbomoso. However, the eighteen communities covered by this study are the immediate localities at the fringe areas of the city and are thus the major receivers of excess population and wastes from the city (figure 1). 


\section{Methodology}

Both primary and secondary data were used for this study. The primary data was collected using a set of structured questionnaire containing variables on housing types, environmental conditions,socioeconomic and demographic characteristics of the respondents; and, their perception of the health effects of city encroachment. A total of 200 respondents representing 19 percent of 1048 total housing units, were selected using stratified random sampling technique in the selected eighteen peri urban communities (Table 1 and figure 1).
Secondary data on incidence and prevalence of environment related ailments were collected from six hospitals which were purposively selected being those located within accessibility range of the peri-urban residents in the areas. A- six month (February -July 2008) record of clinically diagnosed four environment related diseases - malaria, cholera, typhoid, diarhoea, were collected. These are diseases which reconnaissance survey reveals have required data in the sampled hospitals.

Simple descriptive statistical techniques were used for the analysis such as frequencies and percentages.

\section{Fig.1 City Spatial expansion and the Peri-urban communities of Ogbomoso}

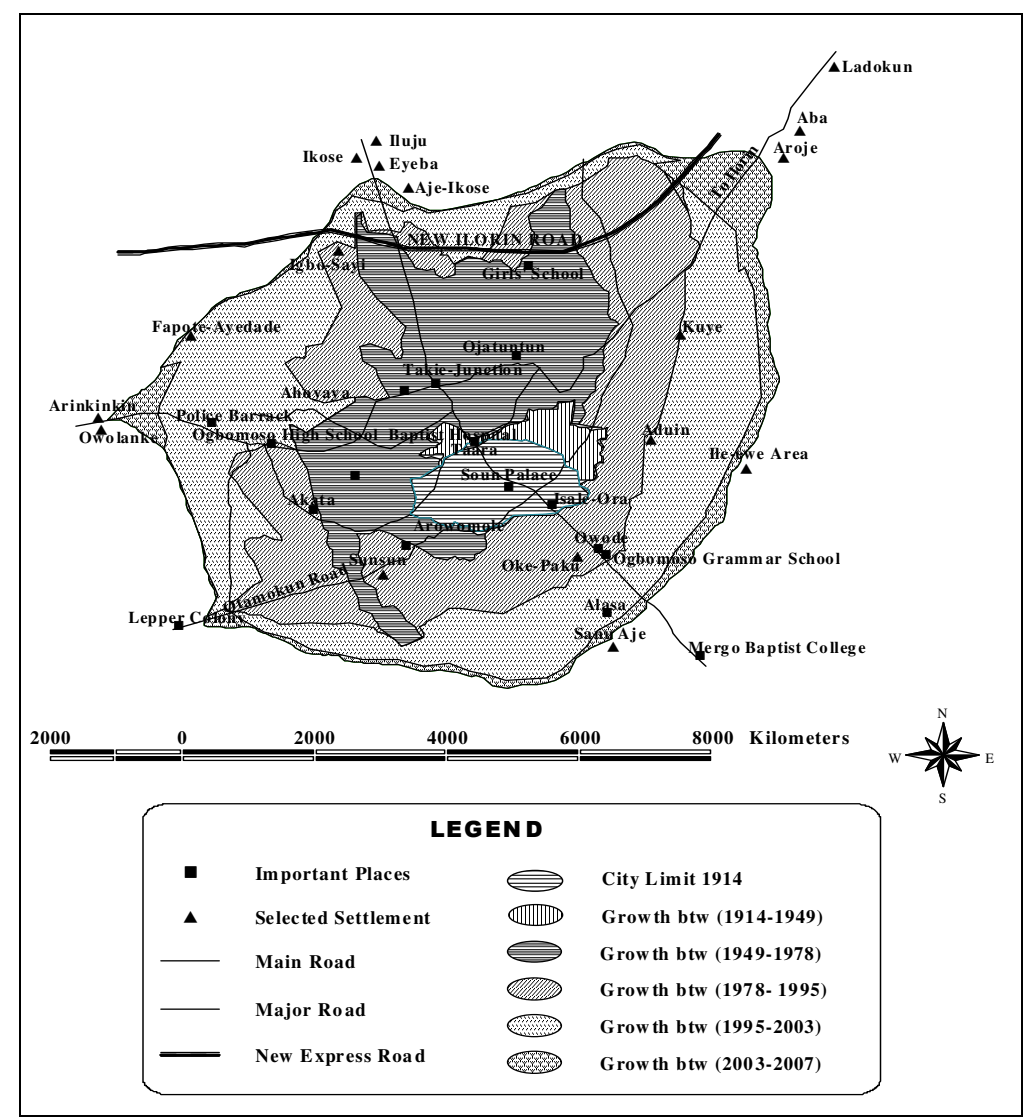

Source Adeboyejo and Abolade 2007 
Results and Discussion Environmental Characteristics of the peri-urban Areas

Type of House

Results show that, about three out of every four building $(72 \%)$ were of the traditional bungalow or "face to face" (Brazilian type of house), followed by one storey building (15\%), and more modern 3bedroom self contained apartment $(11.5 \%)$. A small proportion of the houses were of the traditional mud houses $(1.5 \%)$. The above profile is obtainable in all local governments as Orire, Surulere, Ogbomoso South and Ogbomoso North respectively with $76.9 \%$, $76.5 \%, 76.2 \%$ and $66.7 \%$ had the bulk of their house type as bungalows, which are more or less mere shelter as in most cases facilities such as bathroom, kitchen, toilet are either not provided or are inadequate. As areas of rapid growth, many residential developments were hurriedly put together to escape high rent in the city hence, houses mostly lack essential facilities.

\section{House Ownership Status}

Result of analysis shows that the bulk of the houses were owner occupied $(63.5 \%)$, while $18.5 \%$ of the houses were owned by relatives of respondents. Although no physical cash was paid for accomondation, respondents in relatives' houses were expected to pay in kind through regular maintenance of house environment. Nevertheless, a significant proportion $(18 \%)$ of the houses were rented accommondation. The above profile is particularly observable in all the local governments. In Surulere, Orire, Ogbomoso North and Ogbomoso South, the bulk of the houses were owner occupied with $70.6 \%$. $76.9 \% 64.4 \%$ and $55.6 \%$ respectively.

Availability of Toilet/Bathroom

About $73.5 \%$ of the houses had toilets and bathroom, further analysis reveals that in most cases $(70 \%)$ the toilets were located outside the building and were of the pit toilet type. Toilets and bathrooms were mostly one $(60 \%)$ or two $(38 \%)$ in a house and these were generally shared by more than one household. In few instances toilets and bathrooms were three $(5.7 \%)$ or four $(1.2 \%)$ and were used exclusively by one household. A significant proportion of the houses $(26.5 \%)$ had no toilet with residents relying largely on the "bush system" (nearby bush as toilet) or makeshift bathroom outside the building. The above profile is similar in all the local governments. Availability of Kitchen in Houses

More than half of the houses $(57 \%)$ were without in-built kitchen, in which case cooking is done by residents outside the house, either in the open space or under covered wooden stakes at the back of the building. Apart from Ogbomoso South, where slightly more than half of the houses (52.4\%) had kitchen, the proportion of buildings without kitchen were well above average in Oriire and Ogbomoso North local government respectively with $69.2 \%$ and $61.1 \%$. This proportion was $52.9 \%$ in Suurulere local government. Further analysis and field observations show that the use of balcony and veranda/passage as cooking arena was common.

\section{Water supply}

Clean fresh water is essential for nearly every human endeavour. This includes water for drinking, cooking and washing etc. Its availability in adequate quantity and quality as well as its reliability is a measure of level of socio-economic development and the quality of health status of a community. Result of analysis shows that the bulk of the respondents (99.0\%) did not have access to pipe borne water. This proportion was 100 per cent in Orire and Surulere, while the figures were $98.9 \%$ and $98.4 \%$ respectively in Ogbomoso North and Ogbomoso South local government. This is a major source of concern as lack of access to portable water has serious implication for level of sanitation and health and in particular the prevalence of such water borne disease as typhoid.

Consequent upon the general lack of access to pipe-borne water, the bulk of the respondents $(83.5 \%)$ depended on well water for domestic and other purpose. Other sources of water supply to households were bore hole $(10.5 \%)$ and nearby stream (1.0\%). Some respondents however rely on water vendors $(3.5 \%)$.

In the same vein, communities in Ogbomoso South, Ogbomoso North, Orire and Surulere local governments had $87.3 \%, 83.3 \%$, $84.6 \%$ and $76.5 \%$ of their respondents, using well water as a major source of water. It is however a well known fact that the volume of well water is at its lowest during the dry season. Lack of pipeborne water implies heavy 
burden of scaveging for water in the area by women and children in particular, with its implication on sanitation and health of these vulnerable group of people.

\section{Availability of Refuse Disposal Site}

While the peri-urban areas, are usually the source of food demanded in the cities, they are the destination of wastes generated in the cities. The unsanitary situation in the periurban areas as highlighted by result of analysis reveals that, most respondents had no means of waste collection and disposal as they resorted to the use of nearby vacant land, $(79.5 \%)$ and backyard or open dump sites (17\%). Apart from burning, the management of waste is poor and uncoordinated. This has serious health implications. In the same vein, the bulk of the respondents in the periurban areas dumped waste in nearby bush or vacant land, with $97 \% \quad 95 \% \quad 64.4 \%$ and $61.5 \%$ in Surulere, Ogbomoso South, Ogbomoso North and Orire local government respectively.

\section{Prevalence of Environment Related Communicable Diseases General pattern of Disease}

Result of analysis shown in Table 2 reveals the proportion of respondents who claimed to have suffered from various ailments in the last six months. As reported by the respondents, the most prevalent diseases were malaria (53.5\%) and typhoid (45.2\%). Communities in Ogbomoso south with $92.1 \%$ and $81 \%$ had the largest concentrations of the two diseases, followed by those in Ogbomoso North $(87.8 \%$ of malaria and $72.2 \%$ of typhoid), and Oriire with $61.5 \%$ and $38.5 \%$ of cases. Suburbs in Surulere though had the lowest proportions of malaria and typhoid with $47.1 \%$ and $44.1 \%$, it was the only area with cases of cholera (2.2\%) and Diarhoea (2.2\%).

Profile of Communities on Incidence of Diseases

Table 3 shows the spatial pattern of distribution of disease cases in the periurban communities. The table shows that, all the cholera and diarhoea cases were actually recorded in Abaa, a surburb community along Ilorin road in Surulere local government. In line with general pattern, described in table 2, incidence of malaria and typhoid were high in all the communities, ranging from $40 \%$ to $100 \%$ for malaria and $21 \%$ to $100 \%$ for typhoid. All respondents(100\%) in Iluju, Ladokun, Esaanuaje and almost all (over 90\%) in six other communities had malaria during the period. This result is in line with observation by Sofoluwe et al (2006)to the effect that, populations with malaria are on the increase in the unsanitary fringe areas of urbanizing tropical world, where waste disposal facilities are lacking.

A major factor contributing to malaria in the study area is the indiscriminate dumping of wastes in the grown weeds and bushes. The bulk of the respondents $(79.5 \%)$, enjoy flinging their wastes into the nearest bush. This idea is preferred by them as there is no expenditure or penalty required to be paid for this act.

Also typhoid as an ailment has been found to be more frequently water-borne. The prevalence of typhoid in the study area is not surprising as the majority of the respondents 99\% did not have access to pipe borne water. In the same vein, the major source of water to households were wells $-83.5 \%$. Another major factor for the prevalence of typhoid in the study area, is the distance to the source of drinking water. The majority of the respondents,women in particular trek considerable distances to fetch water either for drinking or other domestic purposes.

Well water as the majority of the respondents $(83.5 \%)$ asserted to be their major source of water, is in its raw state, never safe for drinking unless it is treated. It is the most common source, and raw water is procured and delivered untreated to the residents in the study area. The most important thing is to bring water from far away places practically to the door steps of the ordinary people in as big quantities as possible without belabouring the quality of such supply. The degree of distance to the source of drinking water as affirmed by the respondents to be far can be likened to heavy work done, which makes access to well water strenuous in long trekkable distance,which increases vulnerability to environment related communicable disease.

For further analysis and emphatic conclusions, hospital records of clinically diagnosed cases of the above ailments are examined.

Analysis of hospital records of disease pattern

A major observation is the fact that the incidence of clinically diagnosed cases of diseases followed that reported or perceived by the respondents. As perceived by the respondents, the most prevalent diseases in the study area as revealed by the hospital record are malaria with a total of 13,145 or $(75.4 \%)$ 
and typhoid with 4,183 (24.0\%) cases. Cholera and diarhoea each with 0.1 and $0.4 \%$ of cases were less prevalent as also perceived.

Sex and spatial variations in incidence of the diseases

Table 4 shows the sex differentials as well as the monthly distribution of the two most prevalent diseases - malaria and typhoid cases. It is evident from the table that in both cases, females with $56.5 \%$ and $61.2 \%$ were more vulnerable to malaria and typhoid than their male counterpart. There is however slight temporal variations in the incidence of malaria, as it increased from 1,360 (10.35\%) in febuary (the peak of dry season and scarcity of water) to $13.5 \%$, and $20.6 \%$ in march and april, which are the beginning of raining and planting season and thereafter declined slightly to 20.2 $\%, 19.6 \%$ and $15.6 \%$ respectively in may, june and july, the first peak of raining season when probably the respondents have come to gain more control over carriers of malaria parasites. However except for the months of april and may, more females than males were affected.

Similarly, more females than males are more vulnerable to typhoid attack. This is more so in the first three months of febuary to april, when the proportion of female sufferers of the disease stood at $68.3 \%, 62.8 \%$ and 78.8 $\%$.

From Table 5, the incidence of cholera and typhoid were though sparse, just as the respondents reported, however in both cases, more females ( $65.2 \%$ of cholera and $70 \%$ of diarhoea ) than males suffered from the diseases. Also a total of $23(0.1 \%)$ and 70 $(0.4 \%)$ cases of cholera and diarhoea were recorded within the same period.

The prevalence of cholera and diarhoea is though low but the reported cases were from one local government - in Surulere local government. It should be noted also that it is only the local government where respondents claimed they used stream waters as the major source of water to the household. Cholera is a water borne disease majorly caused by polluted stream water. According to the World Health Organization, (1999) about $80 \%$ of cholera disease are from stream water. The reported cases cholera and diarhoea in Surulere local government, could be traced to poor hygiene with $100 \%$ dwellings not having access to pipeborne water and most dwellings (52\%) not having kitchen. The majority of the inhabitants $(50 \%)$ used balcony or veranda as their kitchen, $26.5 \%$ of the respondents used corridor and a significant proportion of $23.5 \%$ use backyard as their kitchen. These are avenues for flies, cockroaches and rats to perch on their food, and utensils etc. When water is lacking people minimize little available and their hygience is not guaranteed. Sometimes waste water from washing of clothes and even bathroom are stored sometimes for more than a day and later, the water is reused to flush the toilet or do other cleaning exercise. This implies that, no proper hygiene is taken into consideration as regards the cooking of food, washing of utensils and storage of food.

\section{Conclusion}

Health problems are created when the community grows in extent and density without improvement in basic infrastructure. Quality infrastructure services such as safe water, sanitation systems and electricity are essential for sustaining life and maintaining health, but these are generally lacking in the study area. The population has been exposed to serious health hazards especially owing to poor sanitation and unavailability of infrastructural facilities. One aspect of periurban communities of obvious relevance to health is water - its availability in adequate quantity and quality which is so lacking in the communities. Contaminated and impure water is responsible for the transmission of many diseases in the study area, the most important being malaria and typhoid.

It is therefore suggested that: There is the need for layout design and close monitoring of development in areas like Aroje, Abaa,Sunsun to forestall development of slum and squatter settlements. In this vein, urban development planning and management should assume a metropolitan status, where an holistic approach to development control, urban planning and management are pursued within a regional framework.

An adequate, safe and potable water supply, easy of access, is a major factor in raising the health standards of any community and so there is a need for urgent provision of potable water especially in Abaa in Surulere local government area. An effective supply systems would represent a worthwhile and lasting investment which would benefit all by improving hygiene and reducing water -borne diseases. 



\section{References}

Adeboyejo, A.T, and Abolade O (2007)"Household Response to Urban Encroachment on Rural Hinterland in Ogbomoso Urban Fringe". Paper presented to the Pripode Workshop on Urban Population, Development and Environment Dynamics in Developing Countries. June $21^{\text {ST }} 2007$ Nairobi, Kenya.

Adesina (2007) "socio-spatial transformations and the Urban fringe landscape in developing countries" paper presented at the United Nations University Institute for Environment and Human Security (UNU-UHS). Summer Academy on Social Vulnerability and resilience Building Megacity, Germany. July 22-28, 2007

Adriana, A. and Julio, D. (2006) "The Peri Urban Water Poor: Citizens or

Consumers?" Journal of Environment and Urbanization Vol. 18,No (2).

Cunningham W, and Cunningham M. A(2008): Principles of Environmental Science. Fourth edition.gs 220, $334-335$.

Debra et al. (2007): “ The Health Effects of Sprawl". The Robertwood Johnson Foundation Report.

Egunjobi layi (1999 Our Gasping City Inaugural lecture. University of Ibadan. University of Ibadan press

Elizabeth N. (1996): Restoring Urban Infrastructure and Services in Nigeria.Findings, World Bank, African Region No. 62, May 19.

Funnell D.C.(1978 ) "The Role of Small Service centre in Regional and Rural Development; with Special References to Eastern Africa". Chapter 4 pg 77-112 in Developement Planning and Spatial Structure(ed) Allan Gilbert, John Wiley and Sons Ltd. NY

Hall (2002) The Containment of Urban England. Vol. 2 Allen and Unwin. London

Hardoy, J. Mitlin D, and Satterthwaite D (2001) Environemntal Problems in an Urbanizing and Finding Solutions for cities in Africa, Asia and Latin America London, Earthscan Publication
Hughes and Lovei (1999); World Bank 1999, "Urban poor perception of Urbanization and its vices "World Bank Participation Source Book.

Jaiyebo Oluremi (2003) "Women and Household Sustainance: Changing Livelihood and survival strategies in the peri-urban areas of Ibadan" Environmental and Urbanization 15 (i) ; 111-120

Rugg D.S (1972) "Spatial Foundation of Urbanism" WM.C Brown Company. Publishers. Dubuque, Iowa.

Sofoluwe, G.O (2006) Principles and Practice of Public Health in Africa. Vol 1, Second edition; University Press PLC

Valerie Gregg (2000). "Urban Sprawl Processes and Urbanization" .www.goggle.com.accessed January 2009

Van Den Berg L.M; M.S. Van Wiyk and P Van Hoi (2003) " The Transformation of Rural Life Downstream of Hanoi" Environment and Urbanization 15 (1) 35-51

Weber, A.F. (1963) "The Growth of Cities in the Nineteenth Century" Cornell University Press. Ithaca, NY.

World Bank Growth, Poverty and Inequality, 2007.

World Health Organization Final report of twenty - seven session of the W.H.O regional committee for Africa. 2004

Xie Y; Y. Mei and T. Guangin (2005) "Socio Economic Driving forces of Arable Land Conversion: A case study of Wuxian city, China" Globa Environmental change 15 (3) ; 238-252

Xie Y. M.; N. Yu; Y. Bai and X. Xing (2006) "Ecological Analysis of an Emerging Urban Landscape Patern: Desakota, a case study in Souzhous, China" Land Scape Ecology 21 (8) 1297-1309.

Yeats M. and Garner, B (1980) The North American City. NY Harper and Row Publisher 
Table 1 Selected settlements and distribution of questionnaire

\begin{tabular}{|l|l|c|c|}
\hline L.G.A & Settlement & No of Houses & No of Questionniare \\
\hline \multirow{4}{*}{ Ogbomoso } & Aduin & 63 & 12 \\
\cline { 2 - 4 } & Ileewe & 67 & 13 \\
\cline { 2 - 4 } & Igbosayi & 52 & 10 \\
\cline { 2 - 4 } & Oke- Paku & 58 & 11 \\
\cline { 2 - 4 } & Kuye & 57 & 11 \\
\cline { 2 - 4 } & Ikose & 59 & 11 \\
\cline { 2 - 4 } & Eyeba & 73 & 14 \\
\cline { 2 - 4 } & Aaje- Ikose & 55 & 10 \\
\hline \multirow{5}{*}{ Sogbomoso } & Sunsun & 57 & 11 \\
\cline { 2 - 4 } & Sanu- Aje & 57 & 11 \\
\cline { 2 - 4 } & Safejo & 62 & 12 \\
\cline { 2 - 4 } & Arinkinkin & 52 & 10 \\
\cline { 2 - 4 } & Owolaake & 58 & 11 \\
\cline { 2 - 4 } & Fapote- Ayedade & 68 & 13 \\
\hline Surulere & Ladokun & 48 & 9 \\
\cline { 2 - 4 } & Aroje & 52 & 10 \\
\cline { 2 - 4 } & Abaa & 52 & 11 \\
\hline Orire & Iluju & 58 & $\mathbf{2 0 0}$ \\
\hline \multirow{3}{*}{} & Total & $\mathbf{1 0 4 8}$ & \\
\hline
\end{tabular}

Table 2 Variations by Local government areas in proportion of respondents who claimed to have suffered from various ailments in the last six months

\begin{tabular}{|c|c|c|c|c|c|c|c|c|}
\hline \multirow{2}{*}{$\begin{array}{l}\text { LOCAL } \\
\text { GOVTS }\end{array}$} & \multicolumn{8}{|c|}{ AILMENTS SUFFERED } \\
\hline & MALARIA & $\%$ & TYPHOID & $\%$ & CHOLERA & $\%$ & DIARHOEA & $\%$ \\
\hline $\begin{array}{l}\text { OGBOMOSO } \\
\text { NORTH }\end{array}$ & 79 & 87.8 & 65 & 72.2 & - & - & - & - \\
\hline $\begin{array}{l}\text { OGBOMOSO } \\
\text { SOUTH }\end{array}$ & 58 & 92.1 & 51 & 81.0 & - & - & - & - \\
\hline SURULERE & 16 & 47.1 & 15 & 44.1 & 2 & 2.2 & 2 & 2.2 \\
\hline ORIRE & 8 & 61.5 & 5 & 38.5 & - & - & - & - \\
\hline Total & 161 & $\mathbf{5 3 . 5}$ & 136 & 45.2 & 2 & 0.6 & 2 & 0.6 \\
\hline
\end{tabular}


Table 3 Variations in proportion of respondents who claimed to have suffered diseases in the last

\begin{tabular}{|l|l|l|c|l|}
\hline \multirow{3}{*}{ COMMUNITY } & Malaria & Typhoid & Cholera & Diarhoea \\
\cline { 2 - 5 } & $\boldsymbol{\%}$ & $\mathbf{\%}$ & $\boldsymbol{\%}$ & $\mathbf{\%}$ \\
\hline AROJE & 60 & 70 & - & - \\
\hline ABAA & 40 & 50 & 20 & 20 \\
\hline EYEBA & 42.9 & 21.4 & - & - \\
\hline ADWIN & 91.7 & 66.7 & - & - \\
\hline ILEEWE & 61.5 & 38.5 & - & - \\
\hline KUYE & 63.6 & 63.6 & - & - \\
\hline FAPOTE & 92.3 & 61.5 & - & - \\
\hline SUNSUN & 90.9 & 90.9 & - & - \\
\hline OKEPAKU & 90.9 & 81.8 & - & - \\
\hline IGBOSAYI & 80.0 & 60 & - & - \\
\hline ESANU AJE & 100 & 72.7 & - & - \\
\hline LADOKUN & 100 & 66.7 & - & \\
\hline AJE IKOSE & 80 & 90 & - & - \\
\hline ARINKINKIN & 80 & 80 & - & - \\
\hline SAFEJO & 100 & 91.7 & - & - \\
\hline OWOLAKE & 90.9 & 54.5 & - & - \\
\hline IKOSE & 90.9 & 81.8 & - & - \\
\hline ILUJU & 100 & 100 & - & - \\
\hline
\end{tabular}

six months

Table 4:Variations in Incidence of two most prevalent diseases (Malaria and Typhoid ) in last six months

\begin{tabular}{|c|c|c|c|c|c|c|c|c|}
\hline & \multicolumn{5}{|c|}{ Malaria } & \multicolumn{4}{c|}{ Typhoid } \\
\hline Month & Male & \% & Female & \% & Male & \% & Female & \% \\
\hline Feb. & 349 & 25.7 & 1011 & 74.3 & 79 & 31.7 & 170 & 68.3 \\
\hline March & 684 & 38.6 & 1087 & 61.4 & 232 & 37.8 & 382 & 62.2 \\
\hline April & 1401 & 51.5 & 1319 & 48.5 & 150 & 21.2 & 556 & 78.8 \\
\hline May & 1350 & 50.7 & 1311 & 40.3 & 417 & 48.8 & 438 & 51.2 \\
\hline June & 1259 & 48.8 & 1320 & 51.2 & 359 & 41.8 & 499 & 58.2 \\
\hline July & 670 & 32.6 & 1384 & 67.4 & 384 & 42.6 & 517 & 57.4 \\
\hline Total & $\mathbf{5 7 1 3}$ & $\mathbf{4 3 . 5}$ & 7432 & $\mathbf{5 6 . 5}$ & 1621 & 38.8 & 2562 & 61.2 \\
\hline G.Total & \multicolumn{6}{|c|}{$13145(75.4 \%)$} & \multicolumn{5}{c|}{$4183(24.0 \%)$} & \\
\hline
\end{tabular}

Table 5: Sex differentials in Incidence of Cholera and Diarhoea cases

\begin{tabular}{|c|c|c|c|c|c|c|c|c|}
\hline & \multicolumn{5}{|c|}{ Cholera } & \multicolumn{4}{c|}{ Diarhoea } \\
\hline Month & Male & \% & Female & \% & Male & \% & Female & \% \\
\hline Feb. & 0 & 0 & 0 & 0 & 3 & 23.1 & 10 & 76.9 \\
\hline March & 0 & 0 & 9 & 100 & 4 & 28.6 & 10 & 71.4 \\
\hline April & 3 & 100 & 0 & 0 & 6 & 37.5 & 10 & 62.5 \\
\hline May & 5 & 50 & 5 & 50 & 0 & 0.0 & 2 & 100.0 \\
\hline June & 0 & 0 & 1 & 100 & 5 & 22.7 & 17 & 77.3 \\
\hline July & 0 & 0 & 0 & 0 & 3 & 100.0 & 0 & 0.0 \\
\hline Total & 8 & $\mathbf{3 4 . 8}$ & 15 & $\mathbf{6 5 . 2}$ & 21 & 30.0 & 49 & 70.0 \\
\hline & \multicolumn{3}{|c|}{$23(0.1 \%)$} & & \multicolumn{5}{c|}{$70(0.4 \%)$} \\
\hline
\end{tabular}

